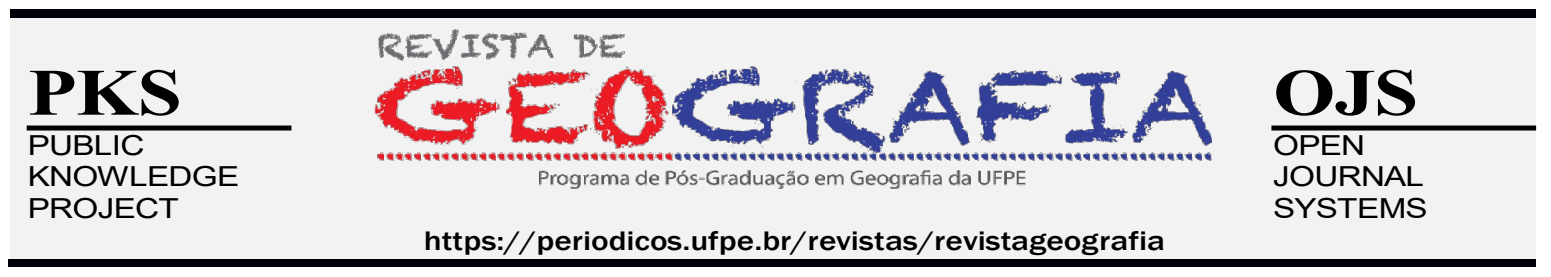

\title{
APLICAÇÃO DE ÍNDICES MORFOMÉTRICOS EM ESCALA DE DETALHE PARA CARACTERIZAÇÃO MORFOTECTÔNICA NA FOLHA ITAPOROROCA 1:25.000, PARAÍBA - BR
}

\author{
Alexandre dos Santos Souza ${ }^{1}$, Larissa Fernandes de Lavor $^{2}$ \\ ${ }^{1}$ Universidade Federal da Paraiba, Email: alesougeo@gmail.com \\ ${ }^{2}$ Universidade Federal de Pernambuco,Email:larylavor@hotmail.com
}

Artigo recebido em 13/01/2020 e aceito em 09/06/2020

\begin{abstract}
RESUMO
As técnicas de morfometria, quando empregadas no estudo do relevo e na rede de drenagem fluvial, permitem inferir sobre os aspectos estruturais que influenciam na configuração de feições morfoestruturais presentes em diferentes bases litológicas. Este trabalho demonstra como aplicar, em carta topográfica de 1:25.000, digitalizada e vetorizada em um sistema de Computer-Aided Design, os índices morfométricos de Razão Fundo/Altura de Vale (RFAV), Fator Assimétrico (FA) e perfis topográficos. As técnicas aplicadas possibilitam apresentar resultados qualitativos e quantitativos que, combinados, resultam em informações detalhadas sobre padrões morfoestruturais presentes no relevo, os quais só podem se registrar por meio de estudos particularizados e com escala de detalhe. No caso específico deste trabalho, registraram-se os principais padrões morfoestruturais existentes na área da folha Itapororoca 1:25.000 (SB.25-Y-A-V-4-NO), borda oriental do estado da Paraíba, entre os quais estão: canais retilíneos, inflexões abruptas, vales assimétricos, entre outros. Os resultados obtidos corroboram outras pesquisas que revisam a concepção ultrapassada de que a plataforma continental brasileira é passiva, demonstrando a presença conspícua da atuação morfotectônica na configuração do relevo brasileiro.
\end{abstract}

Palavras chave: Carta topográfica; morfometria do relevo; morfotectônica; rede de drenagem.

\section{APPLICATION OF MORPHOMETRIC INDEXES IN DETAIL SCALE FOR MORPHOTECTONIC CHARACTERIZATION IN THE ITAPOROROCA SHEET 1:25,000, PARAÍBA - BR}

\begin{abstract}
The morphometric techniques, when used in the study of the relief and in the river drainage network, allow inferring about the structural aspects that influence the configuration of morphostructural features present in different lithological bases. This work demonstrates how to apply, in a topographic chart of 1:25,000, digitized and vectorized in a Computer-Aided Design system, the morphometric indices of Valley Floor Width to Height Ratio (VFWH), Asymmetric Factor (AF) and topographic profiles. The applied techniques make it possible to present qualitative and quantitative results that, when combined, result in detailed information on morphostructural patterns present in the relief, which can only be registered through individualized studies and with a scale of detail. In the specific case of this work, they were registered the main morphostructural patterns existing in the area of the Itapororoca leaf 1:25,000 (SB.25-Y-A-V-4-NO), eastern edge of the state of Paraíba, among which are: rectilinear channels, inflections steep, asymmetric valleys, among others. The results obtained corroborate other studies that revise the outdated conception that the Brazilian continental shelf is
\end{abstract}


passive, demonstrating the conspicuous presence of the morphotectonic action in the configuration of the Brazilian relief.

Keywords: Topographic chart; relief morphometry; morphotectonics; drainage network.

\section{INTRODUÇÃO}

Este trabalho tem por finalidade mostrar como procedimentos acessíveis e práticos podem contribuir com a caracterização de feições morfotectônicas presentes no relevo, mais precisamente de uma porção da borda oriental do Nordeste brasileiro. Os procedimentos utilizados neste estudo permitem inferir, por meio de modelos matemáticos detalhados e escalares, as características morfotectônicas presentes no relevo, uma vez que os cálculos morfométricos possibilitam compreender acerca da influência neotectônica na configuração do relevo atual.

A base de análise desta pesquisa se fundamenta na utilização de uma carta topográfica correspondida pela folha Itapororoca 1:25.000 (SB.25-Y-A-V-4-NO) (Figura 1), desenvolvida pelo Serviço de Cartografia da Divisão de Recursos Naturais da Superintendência de Desenvolvimento do Nordeste (Sudene), na escala de 1:25.000, com equidistância entre as curvas de nível de 10 m (BRASIL, 1974).

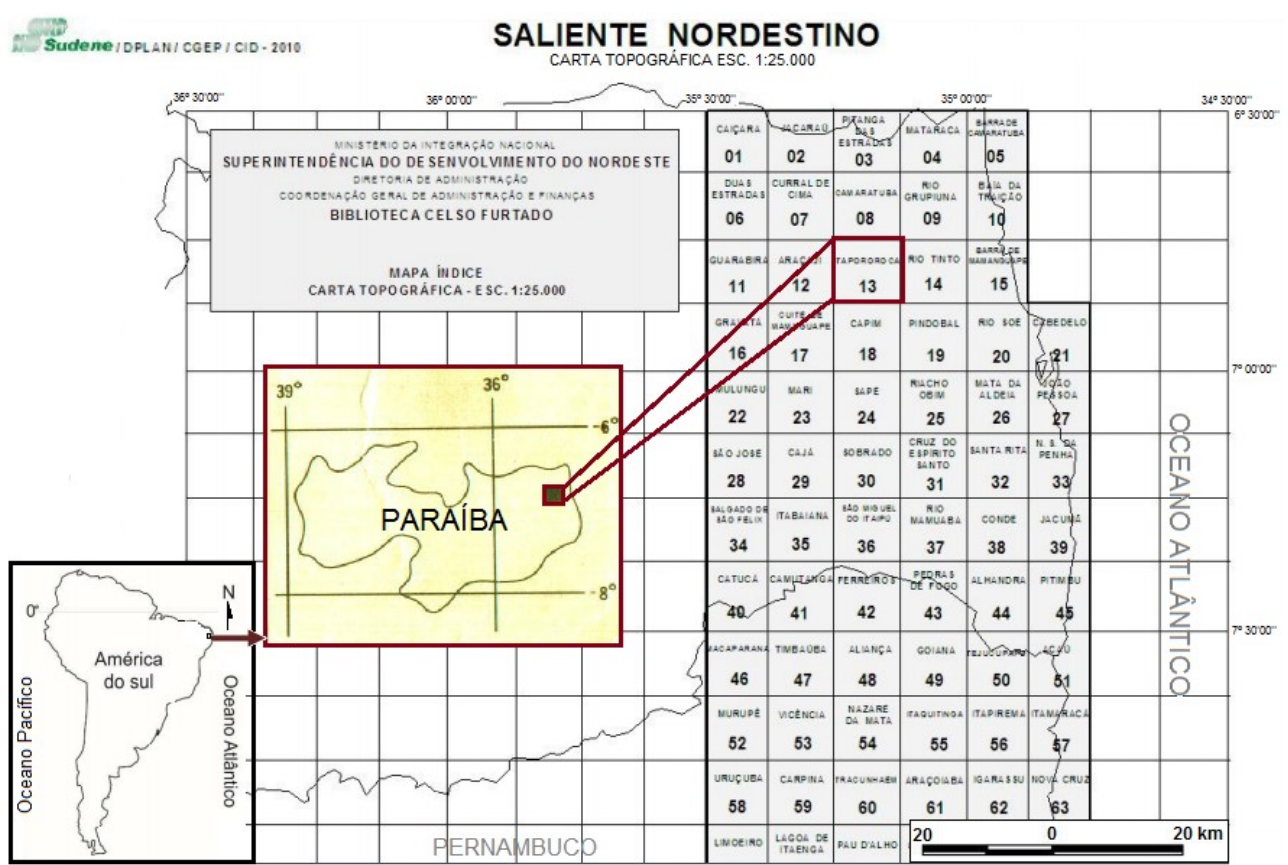

Figura 1. Recorte do Catálogo das Cartas Topográficas do Nordeste do Brasil 1:25.000. Fonte: adaptado de Brasil (2010). 
Estudos apresentados por Bezerra, Mello e Suguio (2006) e Nogueira (2008) comprovam que a margem continental do Nordeste do Brasil é uma das porções sismicamente mais ativas do leste continental da América do Sul, e que essa margem esteve ativa por muito tempo após o rompimento com a margem africana, comprovando que, desde o NeógenoQuaternário, a morfologia da borda oriental do Brasil não foi controlada apenas por eustasia, mas também pela tectônica.

Para Guerra e Guerra (2008), o estudo das formas de relevo e o conhecimento das bases litológicas são de grande relevância, pois permitem aclarar as relações entre os agentes internos e externos do relevo que atuam de maneira integrada, dando origem às variadas feições morfológicas. Para Suguio (2010), pode-se denominar de morfotectônicos os estudos que tenham por finalidade interpretar as relações existentes entre as feições fisiográficas e as estruturas neotectônicas de uma região.

É importante destacar que, na região Nordeste, cujo recorte geológico se caracteriza por fases sucessivas de reativações de falhas (BEZERRA, 1996), percebe-se, por meio de estudos (MAIA; BEZERRA, 2011; MAIA; BEZERRA; CLAUDINO-SALES, 2010), que essas reativações contribuíram de forma significativa ocasionando soerguimentos, modificando a configuração atual do relevo, bem como a rede de drenagem.

Atualmente, as investigações envolvendo as deformações crustais recentes têm ganhado notável aceitação em diversos trabalhos (ALVES; ROSSETTI, 2016; MAIA; BEZERRA, 2014; NASCIMENTO et al., 2013; SILVA; FURRIER, 2019). Todavia, no interior das placas litosféricas, como é o caso do território brasileiro, ainda carecem de um maior entendimento acerca das deformações e dos registros de origem sísmica em tempos recentes e passados (GUEDES et al., 2009).

De acordo com Maia e Bezerra (2011), os estudos no campo da Neotectônica no Brasil começaram a partir da década de 1970, quando alguns pesquisadores ligados à Geotectônica e à Morfotectônica se interessaram em estudar as atividades tectônicas ocorridas do final do Neógeno ao Quaternário, evidenciadas pela morfologia do relevo atual e das estruturas geológicas. Como resultado desses trabalhos, a partir da década de 1990, a antiga concepção apregoada de estabilidade tectônica para a maior parte da plataforma brasileira passou por uma renovação, como os estudos de Riccomini e Assumpção (1999), Lima (2000), Brito Neves et al. (2008), Andrades Filho (2010) e Furrier, Nóbrega e Souza 
(2014). Nos dias atuais, os estudos sobre Neotectônica têm sido cada vez mais precisos e detalhados, em virtude dos avanços das técnicas de medição e datação.

\section{FORMAS DE AVERIGUAÇÃO DE MORFOTECTÔNICA NO RELEVO}

Em terrenos antigos, como é o caso brasileiro, não é simples a possibilidade de se observar planos de falhas recentes na superfície, o que incita a importância de estudos da Neotectônica em busca de evidências mais agudas ou indiretas das eventuais deformações, ou mesmo de seus agentes condicionantes (SILVA et al., 2012). Partindo-se dessa concepção, é possível averiguar que a plataforma brasileira apresenta registros de deformações associadas a linhas de fraqueza. Na região Nordeste do Brasil, por exemplo, essas feições estruturantes se caracterizam por um elevado número de falhas. Por essa razão, faz-se necessária uma abordagem geomorfológica com escala de detalhe a respeito desse quadro (SAADI et al., 2005).

Nessa perspectiva, visando fomentar uma análise qualitativa acerca dos possíveis indícios de morfoestruturais de uma dada região, é indispensável conjugar o uso de cartas topográficas, imagens aéreas e ferramentas de geoprocessamento com expedições de campo. Esses procedimentos permitem ao pesquisador observar possíveis indícios produzidos por esforços tectônicos registrados no relevo, quer seja na topografia, na disposição litológica e no arranjo da rede de canais fluviais. Essa observação é imprescindível tanto para confirmação quanto para desvendamento de tais feições em mapeamentos prévios ou a serem elaborados.

A morfotectônica pode estar impressa no relevo de diversas formas, estando entre as principais feições: desníveis topográficos anômalos, basculamentos, capturas de drenagem, mudanças abrutas de canais por falhamentos, terraços fluviais, facetas triangulares e trapezoidais etc. (ANDRADES FILHO, 2010; ETCHEBEHERE et al., 2007; FURRIER, 2007; SUGUIO, 1998).

Uma feição anômala observada em ambientes afetados pela neotectônica, também muito comum na área estudada, são os blocos basculados, que geralmente resultam de movimentos tectônicos e podem incidir diretamente no direcionamento dos canais fluviais. Um modelo prático dessas feições estruturantes foi apresentado por Martinez (2005), 
demonstrando como o basculamento de blocos pode definir os desníveis topográficos e interferir no traçado da drenagem (Figura 2).

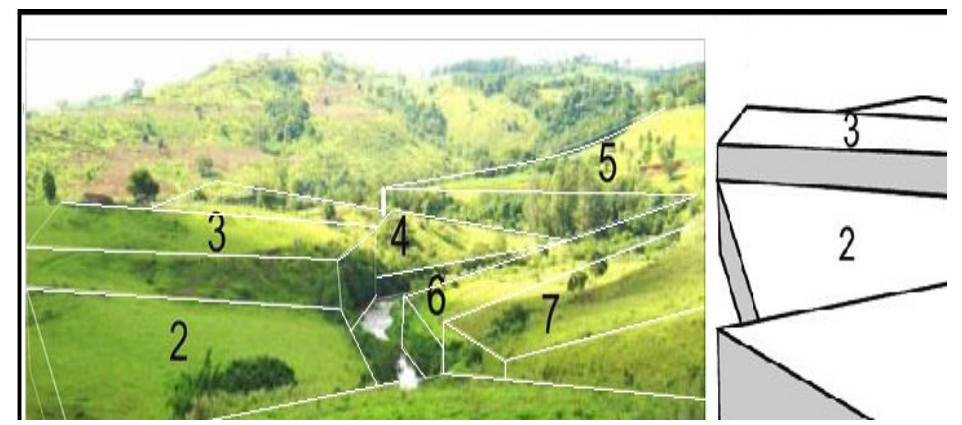

Figura 2. Modelo esquemático demonstrando evidência de tectônica em trecho na adaptação do canal à dinâmica do basculamento de blocos no rio Pirapó - PR. Fonte: Martinez (2005).

Vale ressaltar que se deve interpretar essas estruturas com prudência, procurando se descartar das outras influências que podem dar origem a tais feições, como, por exemplo, a diferenciação da litologia ou erosão diferencial. Para tanto, é importante uma análise morfotectônica amparada numa análise múltipla, com a observação de mapas topográficos, imagens, aplicação de técnicas de geoprocessamento, cálculos morfométricos e visitas de campo, visando reconhecer a importância dos controles litológicos ou mesmo o conhecimento prévio das variações climáticas regionais que contribuem para a elaboração das paisagens.

\section{Avaliação qualitativa de redes de drenagem}

Um método qualitativo bastante utilizado para análise de redes de drenagem foi proposto por Soares e Fiori (1976), que consideram como propriedades importantes numa análise: a densidade (textura que varia de alta a baixa); a sinuosidade (canais curvos e mistos); a angularidade (ângulo de confluência dos elementos de drenagem); a tropia (propriedade dos elementos de drenagem que se desenvolvem segundo uma direção); a assimetria e as formas anômalas (caracterizadas pela presença de elementos com tamanho ou estrutura sistematicamente diferentes).

Associado a esses fatores, Mattos et al. (1982) ponderam que, para interpretação morfoestrutural em rede de drenagem, deve-se considerar no terreno a interação de forças 
endógenas (pretérita ou recente) e exógenas, na qual é possível, por meio de análise e interpretação obtida sobre o relevo e o padrão de drenagem, caracterizar formas anômalas (Figura 3).

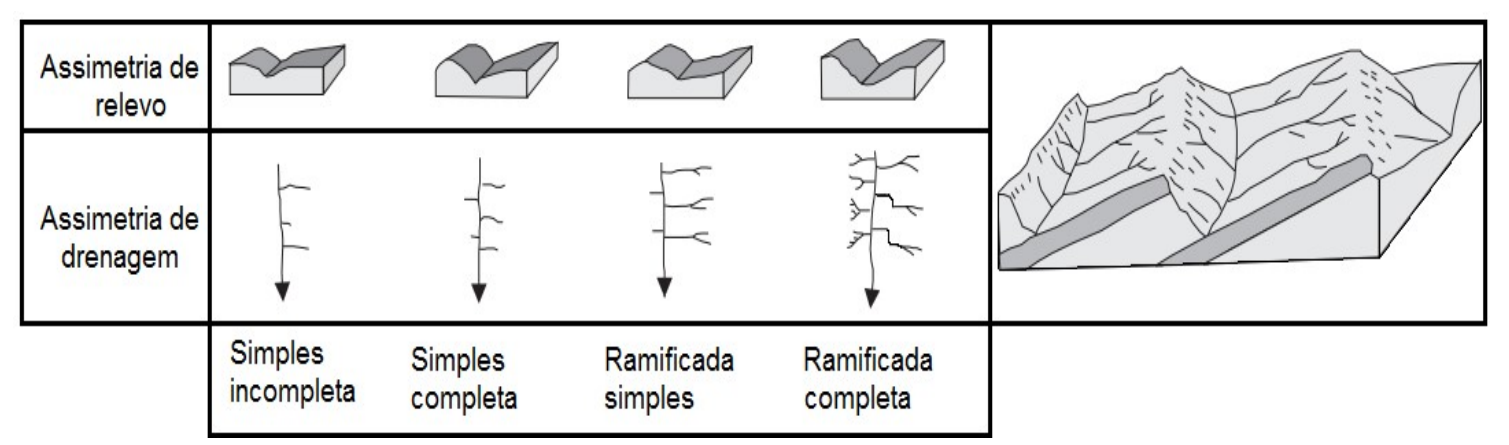

Figura 3. Padrões anômalos nas vertentes e na drenagem. Fonte: adaptado de Mattos et al. (1982).

Outro aspecto importante a respeito das anomalias presentes numa rede de canais é apontado por Corrêa e Fonseca (2010), para os quais, quando observadas em canais de primeira ordem, elas indicam influência de esforços neotectônicos em sua configuração, uma vez que os canais de primeira ordem resultam geralmente de alterações mais recentes ocorridas no relevo. Pode-se observar essas anomalias, por exemplo, em áreas onde ocorrem padrões anelares, canais paralelos e cotovelos na rede de drenagem, que, segundo Andrades Filho (2010), são as anomalias mais comuns nos canais fluviais.

\section{Análise quantitativa}

Nos estudos de avaliação da presença de atividade neotectônica de uma determinada área, a aplicação de parâmetros morfométricos tem conquistado destaque em muitos trabalhos, uma vez que o resultado desses índices pode corroborar substancialmente como indicador da existência de atividade neotectônica numa bacia, bem como das possíveis anomalias presentes na rede de drenagem fluvial.

Nessa perspectiva, trabalhos pioneiros no âmbito da quantificação, como os empreendidos por Horton (1945), Leopold e Maddock Junior (1953) e Strahler (1957), representaram o início de avanços significativos nos estudos que até então se fundamentavam na perspectiva descritiva clássica. Para Florenzano (2008), uma análise quantitativa aplicada por meio de morfometria abrange variáveis pautadas em medições de: 
comprimento, altimetria, declividade, largura, superfície, volume, curvatura, orientação, densidade e frequência de suas formas.

A quantificação dessas variáveis, quando justapostas a índices morfométricos específicos, auxilia na análise morfotectônica. Segundo Andrades Filho (2010), esses índices contribuem na identificação de terrenos submetidos a esforços tectônicos, ressaltando-se que outras causas também possam estar envolvidas.

Concordando com a premissa supracitada, Marques (2007) afirma que os trabalhos de Horton (1945) e Strahler (1957), em direção à morfometria, trouxeram uma perspectiva nova para a Geomorfologia, uma vez que possibilitou a obtenção de resultados pautados na atribuição de valores numéricos referentes à ordenação dos canais fluviais e ao estudo topográfico.

\section{MATERIAIS E MÉTODOS}

Obtiveram-se os dados extraídos da folha Itapororoca (SB.25-Y-A-V-4-NO) a partir da digitalização da carta em formato Joint Photographic Experts Group (JPEG), por meio de escâner, sobre a qual vetorizaram-se, no software Arcgis 5.2, os seguintes elementos: curva de nível, hidrografia e pontos cotados. Optou-se pela vetorização da carta topográfica 1:25.000, por este produto apresentar curvas de nível na equidistância de $10 \mathrm{~m}$, o que resulta em um melhor detalhamento das formas do relevo. Aplicou-se a vetorização visando traçar contornos mais suavizados e bem delineados, que possibilitassem uma representação temática do senso de profundidade necessário à compreensão das pretensões cartográficas do trabalho.

A vetorização manual dos elementos da carta seguiu critérios aplicados por Barbosa e Furrier (2012), segundo os quais permite ao operador ter total controle sobre o traçado estabelecido com o mouse, possibilitando, assim, a obtenção de dados mais precisos. Essa operação permitiu a transformação do arquivo raster digitalizado em vetores, que foram inseridos em softwares específicos, onde se fizeram os cálculos que deram origem aos produtos de análise.

Após a obtenção dos arquivos vetoriais, iniciou-se a fase de georreferenciação em um ambiente de Sistema de Informação Geográfica (SIG) e, em seguida, passou-se por um trabalho de edição para correção de pequenos erros cometidos no processo de vetorização. 
Feito isso, uniram-se e posteriormente recortaram-se os arquivos, restando apenas os dados da área selecionada para o trabalho.

Os índices morfométricos utilizados neste trabalho são os seguintes: Razão Fundo/Altura de Vale (RFAV), desenvolvido por Bull e McFadden (1977); Fator Assimétrico (FA), proposto por Hare e Gardner (1985); e também a elaboração de perfis transversais em vales da rede de drenagem.

\section{Índice da Razão Fundo/Altura do Vale (RFAV)}

Para El Hamdouni et al. (2008), os valores altos de RFAV são geralmente atribuídos a vales com forma de $\mathrm{U}$, e os baixos referem-se a vales em forma de $\mathrm{V}$, sendo utilizados para quantificar a morfologia do canal. Já os valores baixos de RFAV indicam prováveis processos de incisão, possivelmente atrelados a soerguimentos tectônicos. A aplicação equacionária desse índice é consideravelmente simples, e pode ser expressa conforme mostra a Figura 4.

O elemento $V f$ representa a razão entre a largura do fundo e a elevação do vale; o $L f v$ diz respeito ao valor da largura do fundo de vale; o Ade representa a altitude do interflúvio na porção esquerda do vale; o $A d d$ corresponde à altitude do interflúvio da porçãodireita do vale; e o Efv é o valor da média de elevação do fundo do vale (BULL; MCFADDEN, 1977; EL HAMDOUNI et al., 2008).

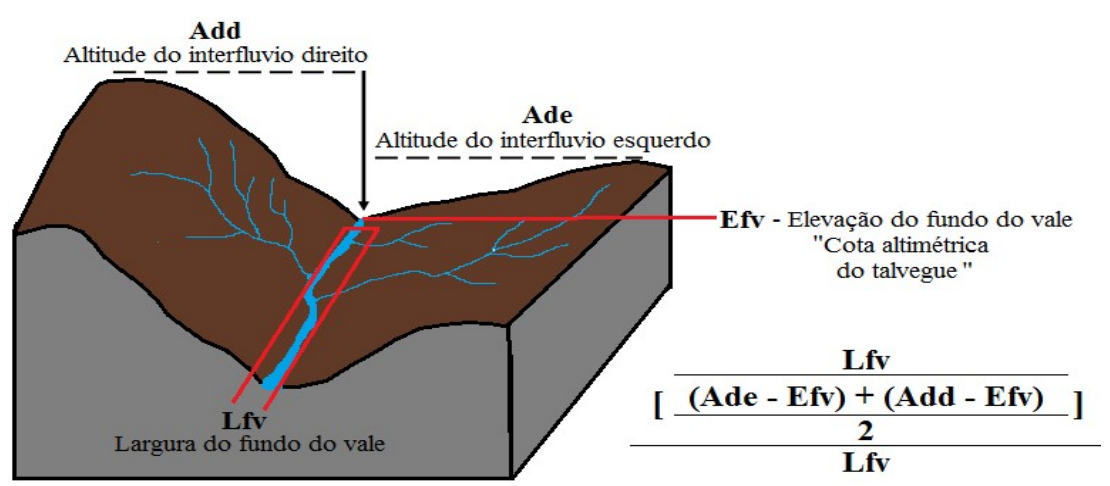

Figura 4. Perfil esquemático de aplicação do método para se encontrar os valores do índice RFAV.

Silva et al. (2003) afirmam que, em geral, os valores de RFAV considerados como indicadores de soerguimento e, consequentemente, de atividade tectônica ativa, são baixos $(<1,0$ - vales em forma de V), enquanto valores que indicam estabilidade tectônica, moldados principalmente pela erosão lateral, são mais altos ( $\geq 1,0$ - vales em forma de $U$ ). 
Segundo os autores, os valores de RFAV variam, dependendo do tamanho da bacia, da descarga de fluxo e do tipo de rocha, e devem ser obtidos em locais com condições geológicas semelhantes.

$\mathrm{Na}$ escolha dos vales para aplicação do RFAV, observam-se na, carta topográfica e em imagem de satélite, os vales com declividades mais acentuadas que apresentavam litologia homogênea em ambas as vertentes e algum tipo de anomalia no padrão do curso. Para obtenção do valor da $E f v$, bastou posicionar o localizador sobre a cota mais baixa do vale estudado. Já para se obter o valor referente à $L f v$, posicionou-se o localizador na parte mais profunda do vale, representada pela cota de menor valor, no seu lado esquerdo, e registrou-se a distância; depois, repetiu-se a operação no lado direito do vale. Como a distância no gráfico aumenta da esquerda para a direita, subtraiu-se o primeiro valor do segundo, tendo como resultado a $L f v$.

A aplicação do cálculo de RFAV, seguindo critérios de Silva et al. (2003), contribuiu para indicar que os valores menores que 1 são indicadores de neotectonismo, enquanto que os valores maiores ou iguais a 1 correspondem a áreas de estabilidade tectônica onde predominam fatores exógenos.

\section{Índice Fator Assimétrico (FA)}

A expressão FA corresponde ao fator assimétrico, $A d$ é a área direita do rio e $A t$ corresponde à área total da bacia de drenagem, e é representada pela seguinte equação: $F A=$ $100(A d / A t)$ (Figura 5). Esse parâmetro morfométrico tem o intuito de aferir a medida de assimetria, definida pela relação de canais das margens direita e esquerda do rio principal (SOUZA; ROSSETI, 2011).

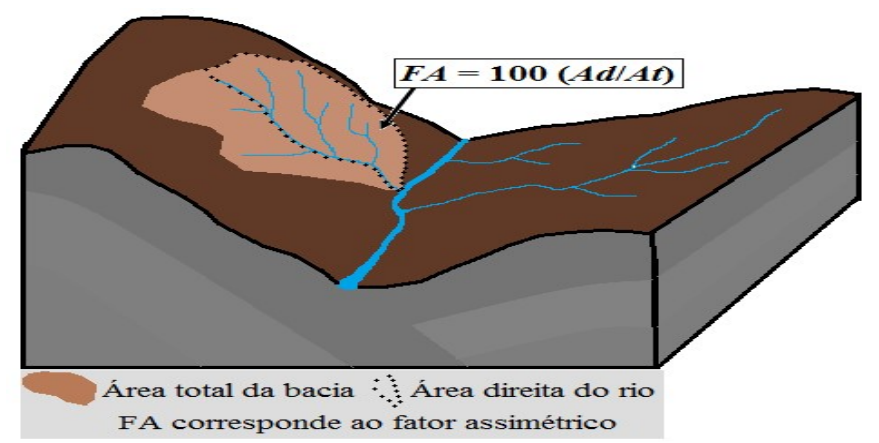

Figura 5. Perfil esquemático da aplicação do método para aferição do índice FA. 
Para Ricón e Vegas (2000), a influência da atividade tectônica é avaliada pelo FA da seguinte forma: quanto mais próximo de 50 for o valor do FA obtido, menor será a influência de atividade tectônica, e vice-versa. Seguindo essa linha, é importante observar que existem condicionantes geológicos, como diferentes resistências impostas pela litologia, que podem deslocar o canal fluvial sem existir atividade tectônica.

De acordo com o mapeamento geológico em escala de detalhe apresentado por Souza e Furrier (2019), observam-se, na área, unidades geológicas distribuídas cronologicamente entre as eras paleoproterozoica e cenozoica (Figura 6).

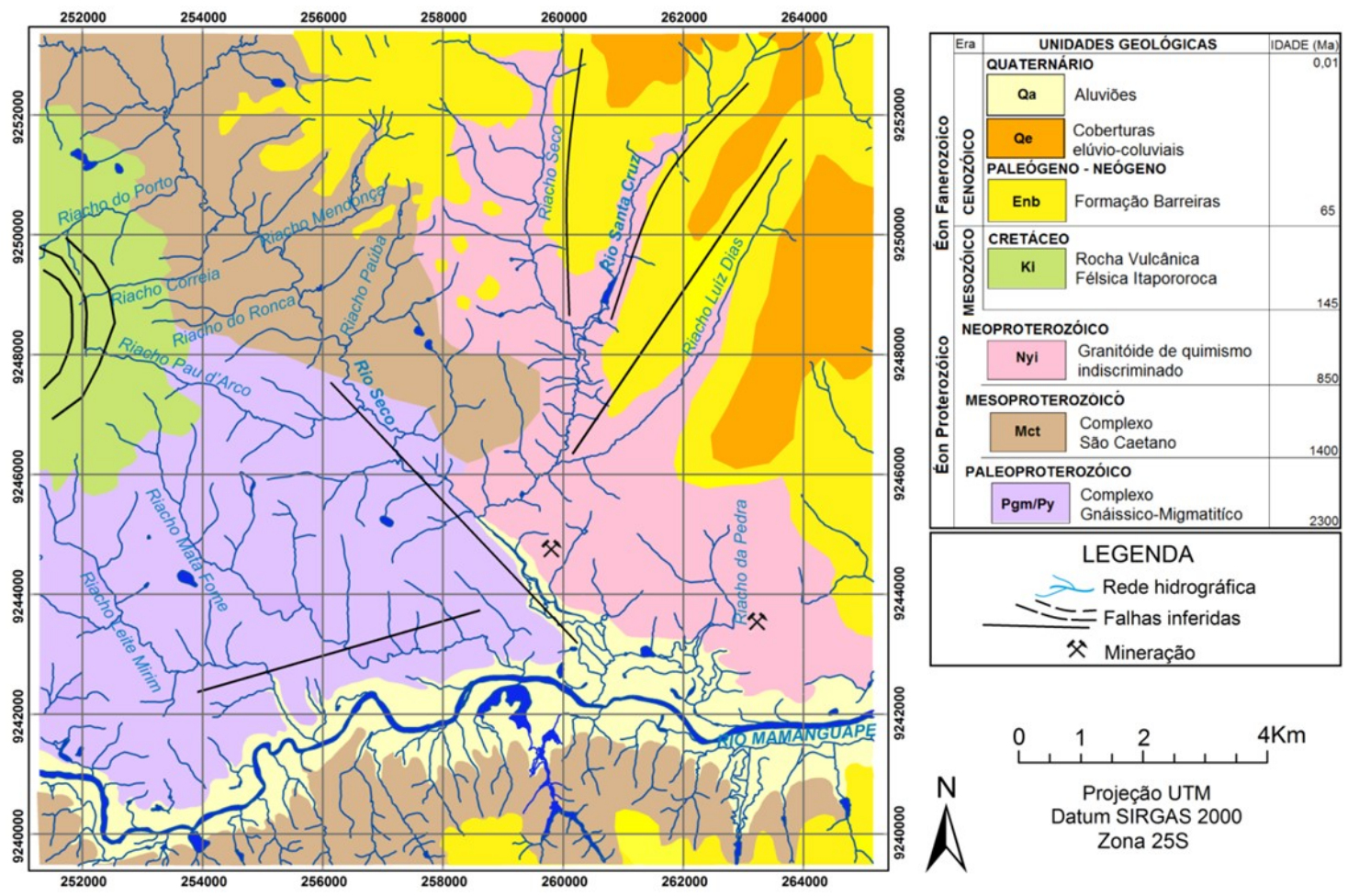

Figura 6. Unidades geológicas da área de estudo. Fonte: Souza e Furrier (2019).

Autores como Brito Neves et al. (2008) e Santos, Ferreira e Silva Júnior (2002) também detalharam em escalas menores (de 1:100.000 e 1:500.000, respectivamente) a situação geológica da região abrangida pela folha Itapororoca, destacando a presença de inúmeros realces de reativações tardias influenciadas pelo Lineamento Patos e, ainda, as falhas normais que alinham o baixo curso do rio Mamanguape, formando um gráben, apresentado com escala de detalhe por Furrier, Nóbrega e Souza (2014).

Além disso, Andrades Filho (2010) destaca que valores de FA muito altos ou muito baixos podem indicar, respectivamente, basculamento à esquerda ou à direita da bacia 
hidrográfica. Segundo o autor, a intensidade da assimetria nas bacias hidrográficas pode ser representada em três classes de valores: assimetria baixa - FA entre 0 a 7; assimetria média - FA entre 7 e 15; e alta assimetria - FA acima de 15. Também se destaca que a assimetria da rede de drenagem se caracteriza pela presença de elementos com tamanho ou estrutura sistematicamente diferentes, de um lado e de outro, do elemento maior. A assimetria fraca se caracteriza apenas por diferença no tamanho dos elementos, e a forte por diferentes tamanhos e formas (SOARES; FIORI, 1976).

\section{RESULTADOS}

Aplicou-se o RFAV e o FA em trechos de canais e sub-bacias presentes em todos os setores da folha Itapororoca. Para avaliação desses parâmetros morfométricos, traçaram-se e delimitaram-se perfis transversais dos vales e das principais sub-bacias da rede hidrográfica da carta topográfica selecionada (Figura 7).

\section{Aplicação do cálculo de RFAV}

Os perfis 1 e 2 (Figura 8), traçados no vale do riacho Luís Dias, apresentam um vale com incisão do talvegue em V com vertentes ligeiramente côncavas (Figura 9), com presença de desnível (degrau) no médio e no baixo curso. Deve-se considerar que, apesar de esse riacho possuir traçado extremamente reto, sentido discordante da drenagem (NE/SW) e estar encaixado em litologia granítica, o trecho também é uma zona de contato com terrenos sedimentares, fato que pode contribuir com o padrão assimétrico das vertentes do vale. Os valores para o RFAV atribuídos para os trechos foram de 0,75 e 1,17, respectivamente, destacando-se como um vale no qual há indícios claros de atividade neotectônica. 
Revista de Geografia (Recife) V. 37, N. 2, 2020

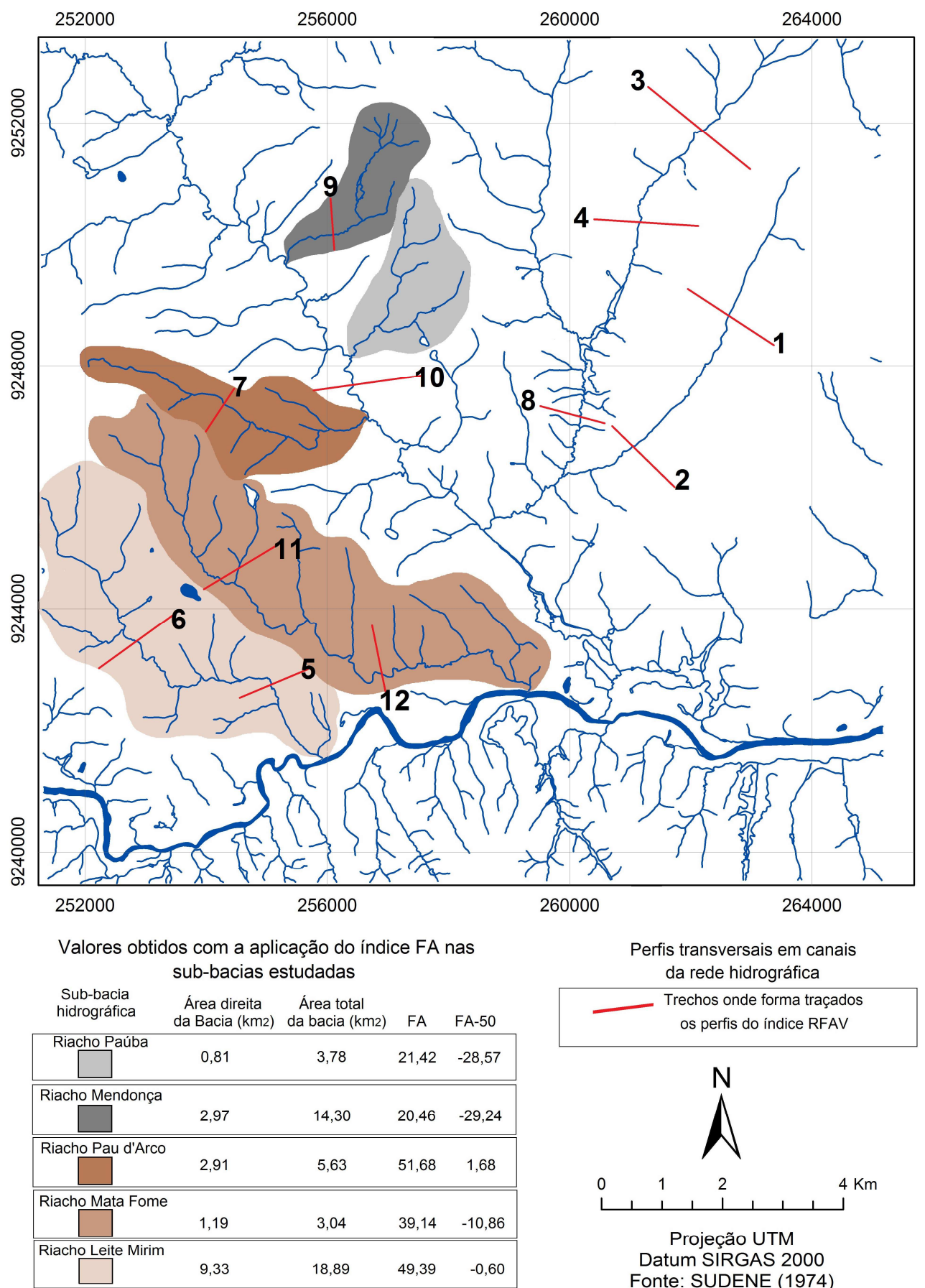

Figura 7. Mapa da rede de drenagem da folha Itapororoca 1:25.000, com indicação dos trechos onde se aplicaram os índices de RFAV e FA. 


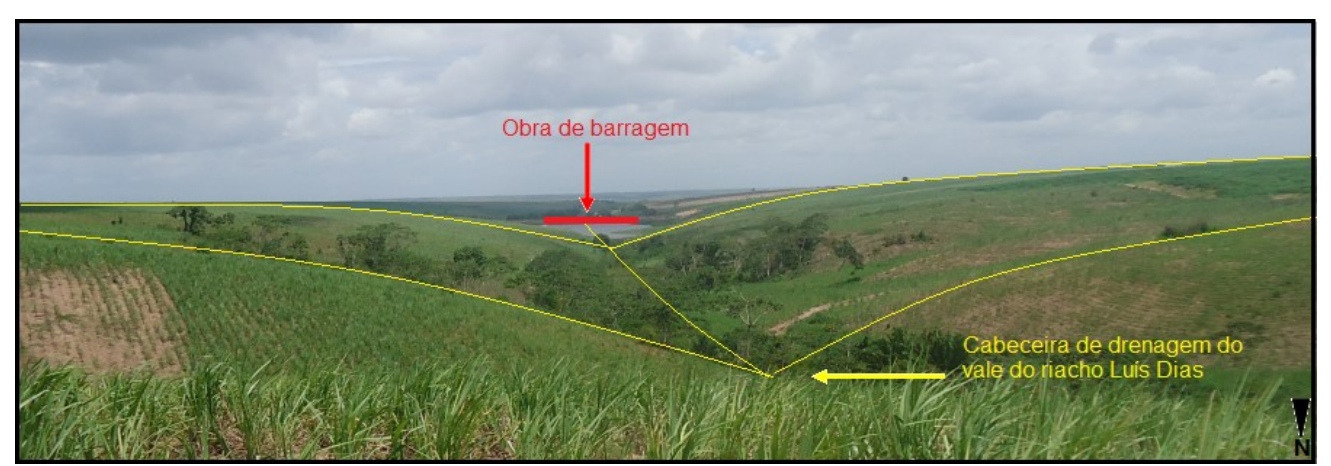

Figura 8. Trecho da cabeceira de drenagem do riacho Luís Dias, porção nordeste da área de estudo.

Também se traçaram os perfis 3 e 4 (Figura 9), numa zona de contato entre os embasamentos cristalino e sedimentar, que até certo ponto explicam a assimetria entre as encostas direita e esquerda do vale. Todavia deve-se considerar os valores expressivos do RFAV de 0,39 e 0,96 para o médio e baixo curso, respectivamente.

Os perfis 5 e 6 (Figura 9), traçados no baixo e alto curso do riacho Leite Mirim, respectivamente, contemplam apenas trechos do embasamento cristalino. Esse canal, conforme já descrito na avaliação qualitativa, apresenta padrões retos e ângulos agudos inflexionados do médio para o baixo curso. Os valores de RFAV apresentados para o trecho foram de 0,56 e 1,40, com destaque para o primeiro trecho (baixo curso), com valor muito abaixo de 1 . 


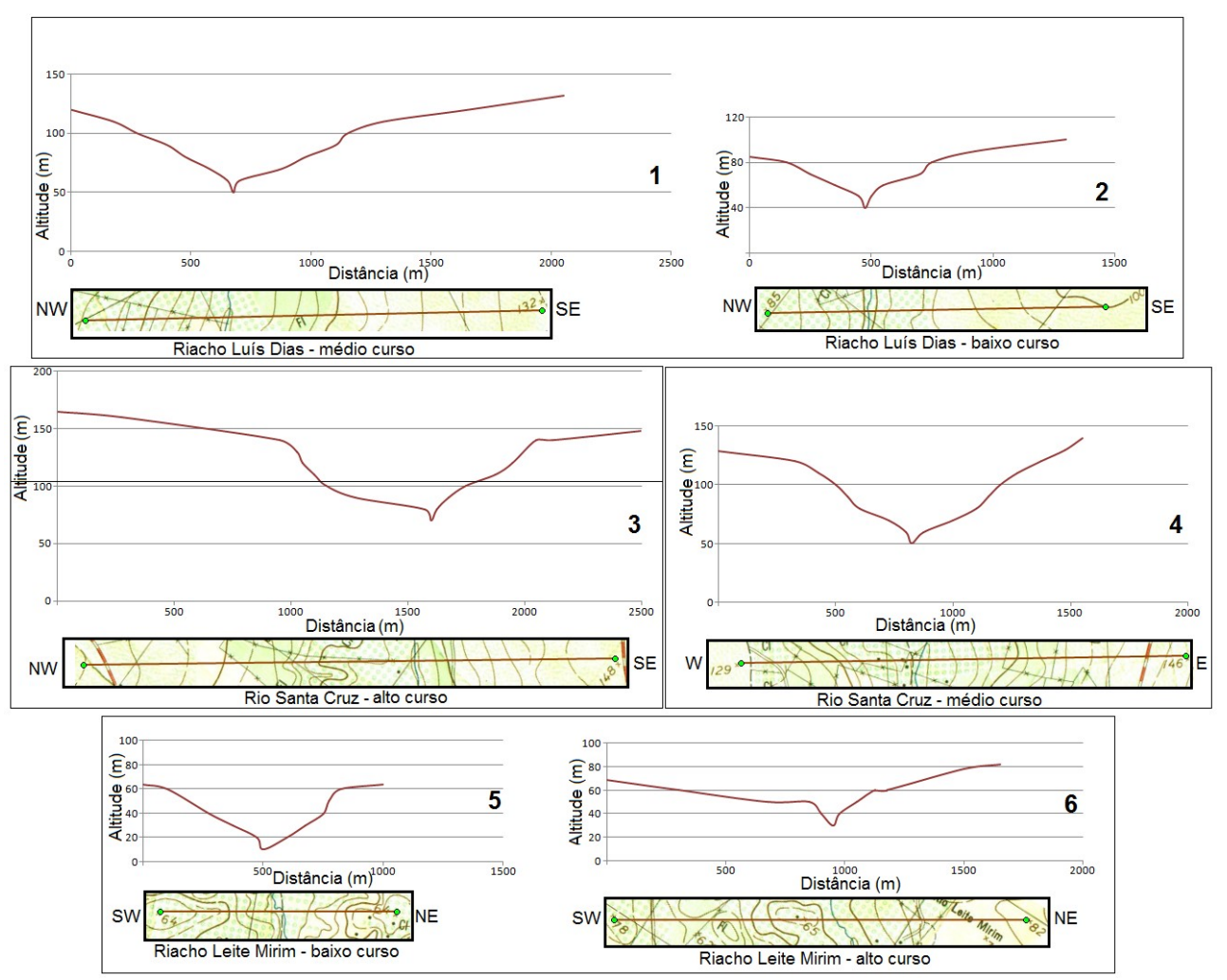

Figura 9. Morfologia dos vales onde se traçaram os perfis de 1 a 6 do índice RFAV. Observa-se exagero vertical dos perfís e de 5 vezes à distância.

Os perfis 7 e 8 (figura 10) traçados sobre os vales dos riachos Pau d'Arco e Pitombeira, respectivamente, apesar de apresentarem indícios de controle estrutural no padrão assimétrico das vertentes, bem como na presença de anomalias expressas por ângulos retos e inflexionados dos canais, apresentaram valores muito próximos a 1, mais precisamente 1,02 para o alto curso do riacho Pau d'Arco e 1,07 para o médio curso do riacho Pitombeira.

Para o perfil 9 (figura 10), elaborado no baixo curso do riacho Mendonça, observou-se a assimetria entre as vertentes direita e esquerda, que configuram um vale em $\mathrm{V}$ encaixado sobre embasamento cristalino, o trecho aferido apresentou um valor expressivo inferior a 1 , mais precisamente 0,62 atestando a possibilidade de controle estrutural na configuração do vale.

O perfil 10 (Figura 10), traçado no médio curso do rio Seco, numa zona de contato entre litologias de rochas do embasamento cristalino, apresenta valor de RFAV de 0,92. Esse índice, associado ao padrão anômalo desse rio e de seus afluentes, além da assimetria presente nas encostas do vale que o confina, corrobora a possibilidade de controle estrutural. 
No caso do riacho Mata Fome (perfis 11 e 12), o RFAV indicou controle neotectônico para o alto curso, com valor de 0,78 , e 1,13 para o médio curso. Esse riacho apresenta forte assimetria entre as margens direita e esquerda, sendo possível averiguar que todos os afluentes estão postos na margem esquerda, com tropia unidirecional e padrão retilíneo, além da presença de cotovelos em pontos distintos do canal principal (Figura 11).

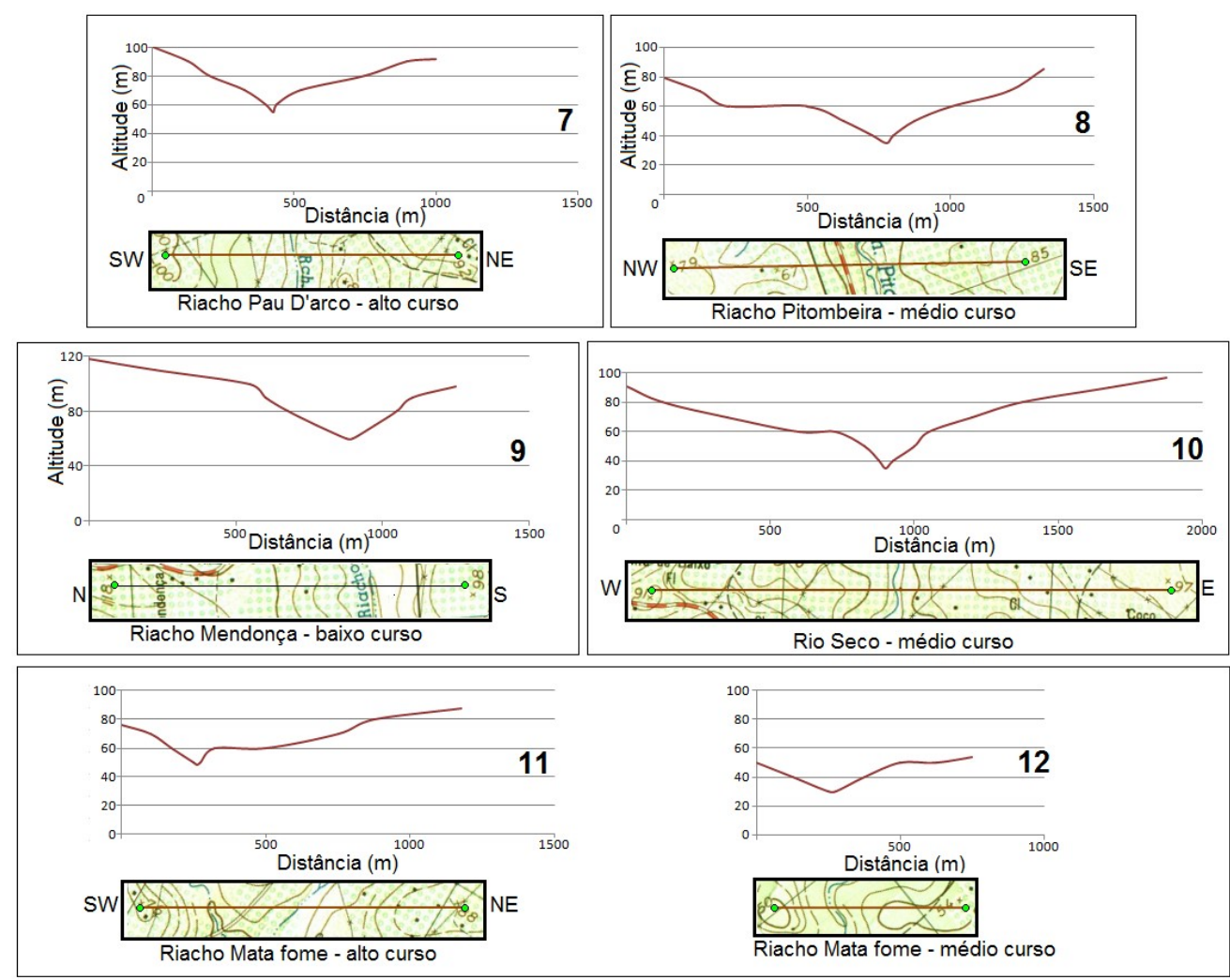

Figura 10. Morfologia dos vales onde se traçaram os perfis de 7 a 12 do índice RFAV. Observa-se exagero vertical dos perfis e de 5 vezes à distância. 


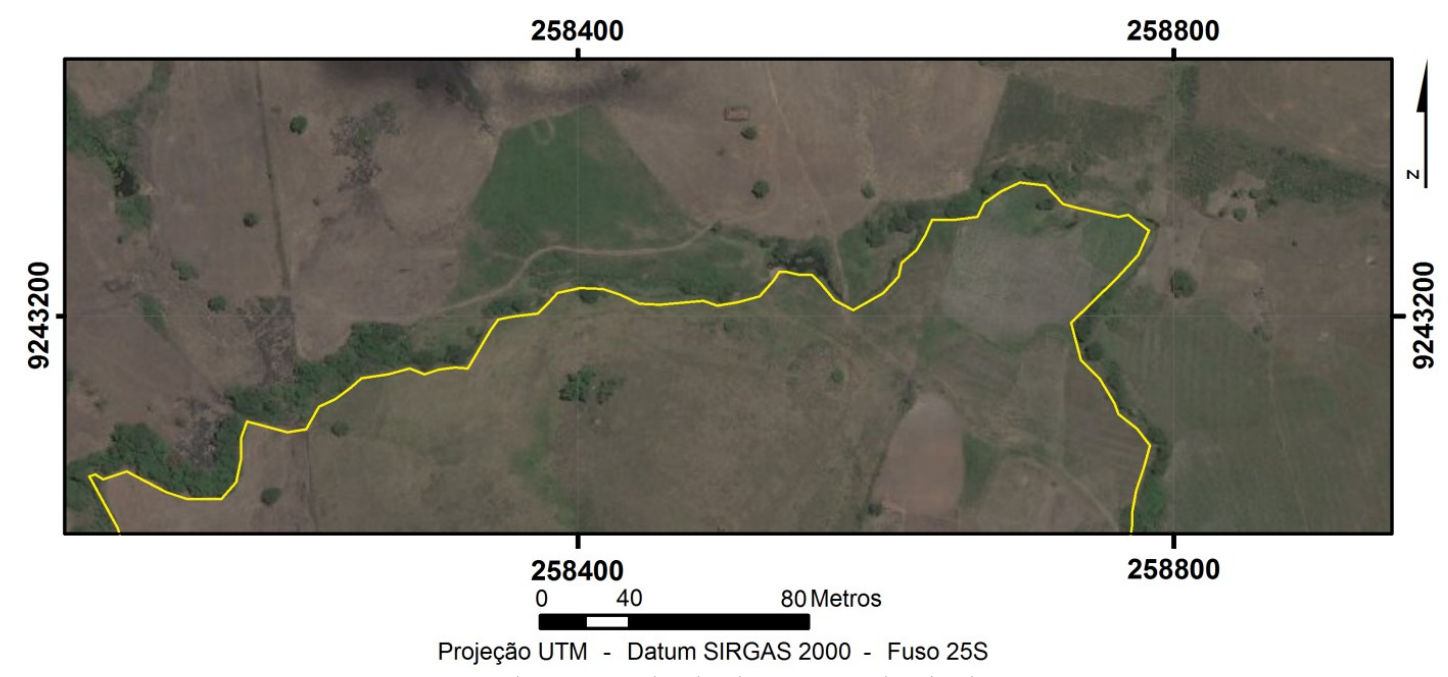

Figura 11. Trecho anômalo da drenagem do riacho Mata Fome.

\section{Índice Fator Assimétrico (FA)}

Aplicou-se o índice FA nas sub-bacias dos riachos Mendonça, Paúba, Pau d'Arco, Mata Fome e Leite Mirim (Figura 12), considerando-se que as bacias hidrográficas com assimetria baixa correspondem a valores de FA entre 0 a 7, assimetria média com FA entre 7 a 15 e com alta assimetria com FA maior que 15. Os índices referentes ao Af para as respectivas sub-bacias variaram de $-0,60$ a $-29,24$ (Tabela 1), evidenciando, segundo os padrões estabelecidos pela literatura especializada, zonas com baixa, média e alta assimetria. 


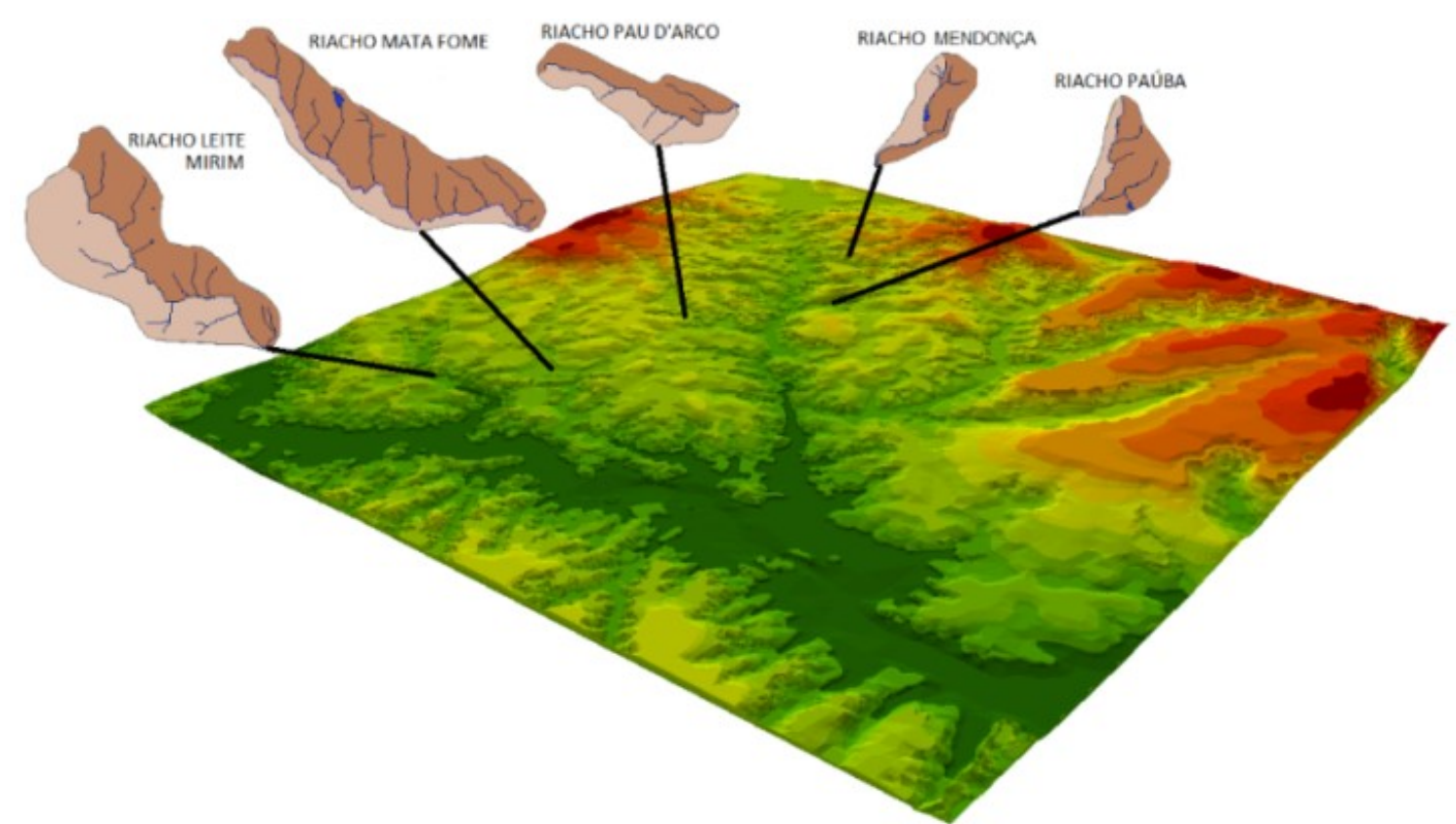

Figura 12. Sub-bacias selecionadas para aplicação do índice FA.

Tabela 1 - Valores obtidos com a aplicação do índice FA nas sub-bacias estudadas

\begin{tabular}{lccrr}
\hline $\begin{array}{c}\text { Sub-bacia } \\
\text { hidrográfica }\end{array}$ & $\begin{array}{c}\text { Área direita da bacia } \\
\left(\mathbf{k m}^{\mathbf{2}} \mathbf{)}\right.\end{array}$ & $\begin{array}{c}\text { Área total da bacia } \\
\mathbf{( k m}^{\mathbf{2}}\end{array}$ & FA & FA-50 \\
\hline Riacho Mendonça & 2,97 & 14,30 & 20,46 & $\mathbf{- 2 9 , 2 4}$ \\
Riacho Paúba & 0,81 & 3,78 & 21,42 & $\mathbf{- 2 8 , 5 7}$ \\
Riacho Pau d'Arco & 2,91 & 5,63 & 51,68 & $\mathbf{1 , 6 8}$ \\
Riacho Mata Fome & 1,19 & 3,04 & 39,14 & $\mathbf{- 1 0 , 8 6}$ \\
Riacho Leite Mirim & 9,33 & 18,89 & 49,39 & $\mathbf{- 0 , 6 0}$ \\
\hline
\end{tabular}

Nota: resultados em vermelho $=$ assimetria alta; em azul $=$ assimetria média; em preto $=$ assimetria baixa.

Os valores de FA mais expressivos, considerados de alta variação assimétrica, registraram-se nas sub-bacias dos riachos Mendonça e Paúba, com variação de -29,24 e 28,57, respectivamente, evidenciando basculamento da margem esquerda. Esses valores, somados às formas retilíneas, dendríticas e paralelas encontradas nos afluentes das margens esquerda desses riachos, reforçam a hipótese de a configuração assimétrica dessas subbacias ser resultado da atuação de eventos neotectônicos.

$\mathrm{Na}$ sub-bacia do riacho Mata Fome, considerou-se média a variação de assimetria obtida, cujo valor para o trecho correspondeu a 10,86. Percebe-se forte basculamento da margem esquerda influenciando no padrão retilíneo e paralelo dos tributários arranjados majoritariamente nessa margem.

Os riachos Leite Mirim e Pau d'Arco apresentaram valores de baixa assimetria, com índices de $-0,60$ e 1,68, respectivamente. Todavia, deve-se destacar que esses canais 
apresentaram fortes evidências de controle estrutural na análise qualitativa dos padrões de drenagem neles presentes.

\section{CONSIDERAÇÕES FINAIS}

As técnicas aplicadas neste trabalho possibilitaram apresentar resultados que expuseram diversas anomalias na área de estudo, indicando que a região foi afetada por falhamentos e esforços compressivos que definiram diversas anomalias, como: padrões de drenagem retilíneos, em treliça e subtipos associados; inflexões abruptas de canais formando ângulos ortogonais; e falhamentos morfoestruturais com orientação compatível com estruturas tectônicas regionais do Nordeste brasileiro.

Dessa forma, a partir de tais evidências e valores obtidos com a aplicação dos parâmetros morfométricos, constatou-se, com escala de detalhe, os padrões morfotectônicos presentes na área estudada. A aplicação dos parâmetros morfométricos apresentou valores que corroboraram as evidências supracitadas, comprovando que as formas do relevo e a rede de drenagem da área indicam, de forma conspícua, a presença de controle estrutural.

Cabe destacar que a aplicação dos índices morfométricos seguiu a metodologia aplicada sobre margens continentais do tipo ativa, todavia seu emprego em regiões da plataforma brasileira tem constatado, com propriedade, a ação tectônica na configuração do relevo.

Vale salientar que esta pesquisa não representa o único meio de análise morfoestrutural sobre o relevo. Trabalhos amparados em técnicas de elaboração de mapas temáticos, geoprocessamento, aplicação de outros índices morfométricos, sismológicos, geofísicos, históricos, arqueológicos, geomorfológicos e geológicos, têm sido desenvolvidos por pesquisadores em muitos contextos.

Dessa forma, considerando-se a pertinência de tais estudos, é fundamental que todos se integrem no afã de apresentarem informações que corroborem o conhecimento pormenorizado sobre o padrão morfotectônico existente no relevo do Brasil.

Em suma, ressalta-se que, quanto maior a escala empregada, maior será a possibilidade de observação e entendimento da morfologia e das peculiaridades físicas do terreno. Trabalhos nesta linha propiciam ampliar pesquisas direcionadas a apresentar dados 
que visam ampliar, juntamente como outros trabalhos, as possibilidades de planejamento do uso correto da paisagem.

\section{REFERÊNCIAS}

ALVES, F. C.; ROSSETTI, D. F. Influência neotectônica no estabelecimento dos vales dos rios Paraíba e Mamanguape, norte da bacia Paraíba (PB). Rev. Bras. Geomorf. (Online), v. 17, n. 3, p. 517-532, 2016.

ANDRADES FILHO, C. O. Análise morfoestrutural da porção central da bacia Paraíba (PB) a partir de dados MDE-SRTM e ALOS-PALSAR FBD. 2010. Dissertação (Mestrado em Sensoriamento Remoto) - Instituto Nacional de Pesquisas Espaciais, São José dos Campos, SP, 2010.

BARBOSA, T. S.; FURRIER, M. Avaliação morfológica e morfométrica da bacia hidrográfica do rio Marés - PB, para verificação de influência neotectônica. Cad. Geoc. (Salvador, Online), v. 9, n. 2, p. 112-120, 2012.

BEZERRA, F. H. R.; MELLO, C. L.; SUGUIO, K. A Formação Barreiras: recentes avanços e antigas questões. Geol. USP, Sér. Cient. (Online), v. 6, n. 2, p. III-VI, 2006.

BEZERRA, P. E. L. Neotectônica e morfogênese da região de Carolina (MA, TO), bacia do Parnaíba. 1996. Dissertação (Mestrado em Geografia) - Universidade Federal do Pará, Belém, 1996.

BRASIL. Superintendência de Desenvolvimento do Nordeste. Divisão de Recursos Naturais. Serviço de Cartografia. Folha Itapororoca (SB.25-Y-A-V-4-NO). Recife: Sudene, 1974. 1 carta topográfica. Escala 1:25.000.

BRASIL. Superintendência de Desenvolvimento do Nordeste. Divisão de Recursos Naturais. Serviço de Cartografia. Saliente Nordestino: carta topográfica. Recife: Sudene, 2010. 1 carta topográfica. Escala 1:25.000.

BRITO NEVES, B. B.; MANTOVANI, M. S. M.; MORAES, C. F.; SIGOLO, J. B. As anomalias geológicas e geofísicas da área norte de Itapororoca-PB, Folha Guarabira. Rev. Bras. Geoc., v. 38, n. 1, p. 1-23, 2008. 
BULL, W. B.; MCFADDEN, L. D. Tectonic geomorphology north and south of the Garlock fault, California. In: GEOMORPHOLOGY SYMPOSIUM-GEOMORPHOLOGY IN ARID REGIONS, 8., 1977, Binghamton. Proceedings [...] Binghamton: Doehring, D.O., 1977. p. 115-138.

CORRÊA, A. C. B.; FONSÊCA D. N. Lineamentos de drenagem e de relevo como subsídio para a caracterização morfoestrutural e reativações neotectônicas da área da bacia do rio Preto, serra do Espinhaço Meridional - MG. Rev. Geogr. (Recife, Online), v. especial VIII Sinageo, n. 1, p. 72-83, 2010.

EL HAMDOUNI, R.; IRIGARAY, C.; FERNÁNDEZ, T.; CHACÓN, J.; KELLER, E. A. Assessment of relative active tectonics, southwest border of the Sierra Nevada (southern Spain). Geomorphology, v. 96, p. 150-173, 2008.

ETCHEBEHERE, M. L. C.; SAAD, A. R.; BISTRICHI, C. A.; GARCIA, M. J.; SILVA, M. F. DA.; BEDANI, E. DE F. Modelo de evolução geológica da região do atual município de Atibaia (SP) durante o Cenozóico. Revista UnG. Geociências, v .6, n. 1, p. 4-31, 2007.

FLORENZANO, T. G. Introdução à geomorfologia. In: FLORENZANO, T. G. (Org.) Geomorfologia: conceitos e tecnologias atuais. São Paulo: Oficina de Textos, 2008. Cap. 1, p. 11-30.

FURRIER, M. Caracterização geomorfológica e do meio físico da folha João Pessoa 1:100.000. 2007. Tese (Doutorado em Geografia) - Universidade de São Paulo, São Paulo, 2007.

FURRIER. M.; NÓBREGA, W. R.; SOUZA, A. S. Análise morfométrica e morfotectônica do gráben do rio Mamanguape e adjacências, borda oriental do Estado da Paraíba, Brasil. Rev. Dep. Geogr. (Online), v. 28, p. 25-38, 2014.

GUEDES, I. C.; ETCHEBEHERE, M. L. C.; MORALES, N.; STEVAUX, J. C.; SANTONI, G. C. Análise morfotectônica da bacia do rio Santo Anastácio, SP, através de parâmetros fluviomorfométricos e de registros paleossísmicos. Geociências, v. 28, n. 4, p. 247-362, 2009.

GUERRA, A. T.; GUERRA, A. J. T. Novo dicionário geológico-geomorfológico. 6. ed. Rio de Janeiro: Bertrand Brasil, 2008. 
HARE, P. W.; GARDNER, I. W. Geomorphic indicators of vertical neotectonism along converging plate margins, Nicoya Peninsula, Costa Rica. In: MORISAWA, M.; HACK, J. T. (Eds.). Tectonic geomorphology: proceedings of the 15th Annual Geomorphology Symposia Series. Binghamton, 1985. p. 76-104.

HORTON, R. E. Erosional development of stream sand their drainage basin: hydrographical approach to quantitative morphology. Geol. Soc. Am. Bull, v. 56, n. 3, p. 275-370, 1945.

LEOPOLD, L. B.; MADDOCK JUNIOR., T. The hydraulic geometry of stream channels and some physiographic implications. Geological Survey Professional Paper, n. 252, p. 1$56,1953$.

LIMA, C. C. U. O neotectonismo na costa do Sudeste e do Nordeste brasileiro. Revista de Ciência e Tecnologia, n. 15, p. 91-102, 2000.

MAIA, R. P.; BEZERRA, F. H. R. Neotectônica, geomorfologia e sistemas fluviais: uma análise preliminar do contexto nordestino. Rev. Bras. Geomorf. (Online), v. 12, n. 3, p. 37 46, 2011.

MAIA, R. P.; BEZERRA, F. H. R. Tópicos de geomorfologia estrutural: Nordeste brasileiro. Fortaleza: Edições UFC, 2014.

MAIA, R. P.; BEZERRA, F. H. R. CLAUDINO-SALES, V. Geomorfologia do Nordeste: concepções clássicas e atuais acerca das superfícies de aplainamento nordestinas. Rev. Geogr. (Recife, Online), v. especial VIII Sinageo, n. 1, p. 6-19, 2010.

MARQUES, J. M. Ciência geomorfológica. In: GUERRA, A. J. T.; CUNHA, S. B. Geomorfologia: uma atualização de bases e conceitos. 7. ed. Rio de Janeiro: Bertrand Brasil, 2007. p. 23-45.

MARTINEZ, M. Aplicação de parâmetros morfométricos de drenagem na bacia do Rio Pirapó: o perfil longitudinal. 2005. Dissertação (Mestrado em Geografia) - Universidade Estadual de Maringá, Maringá, PR, 2005.

MATTOS, J. T.; BALIEIRO, M. G.; SOARES, P. C.; BARCELLOS, P. E.; MENESES, P. R.; CSORDAS, S. M. Análise morfoestrutural com uso de imagens MSS/Landsat e Radar para pesquisa de hidrocarbonetos no Estado de São Paulo. São José dos Campos: INPE, 1982. (Relatório INPE-2445-RTR/015). 
NASCIMENTO, E. R.; SALAMUNI, E.; QUEIROZ, G. L.; SILVA, P. A. H.; FIORI, A. P. Evidências de determinação morfotectônica e neotectônica no relevo da Serra do Mar no Estado do Paraná. Rev. Bras. Geomorf. (Online), v. 14, n. 3, p. 287-299, 2013.

NOGUEIRA, F. C. C. Estruturas tectônicas cenozoicas na porção leste da Bacia Potiguar RN. 2008. Tese (Doutorado em Geodinâmica e Geofísica) - Universidade Federal do Rio Grande do Norte, Natal, 2008.

RICCOMINI, C.; ASSUMPÇÃO, M. Quaternary tectonics in Brazil. Episodes, v. 22, n. 3, p. 221-225, 1999.

RINCÓN, P. J.; VEGAS, R. Aplicación de índices geomorfológicos de actividad tectónica reciente en el antepaís Bético. Geogaceta, v. 27, p, 139-142, 2000.

SAADI, A; BEZERRA, F. H. R; COSTA, F. D; IGREJA, H. L. S; FRANZINELLI, E. Neotectônica da plataforma brasileira. In: SOUZA C. R. G.; SUGUIO, K.; OLIVEIRA A. M. S.; OLIVEIRA, P. E. (Eds.). Quaternário do Brasil. Ribeirão Preto: Holos, 2005. p. 211-234

SANTOS, E. J.; FERREIRA, C. A.; SILVA JÚNIOR, J. M. F. (Org.). Geologia e recursos minerais do estado da Paraíba. Recife: CPRM, 2002.

SILVA, G. P. R.; ETCHEBEHERE, M. L.; SAAD, A. R.; FRANCO-MAGALHÃES, A. O. B. Análise de perfis segmentados de drenagem para a avaliação morfotectônica na bacia hidrográfica do alto rio Jaguari (SP-MG). Geociências, v. 31, n. 2, p. 259-271, 2012.

SILVA, I. C.; FURRIER, M. Análise morfológica e morfométrica das sub-bacias dos rios Cascata e Tinto, Litoral Norte do Estado da Paraíba - Brasil. Rev. Bras. Geomorf. (Online), v. 20, n. 2, p.239-254, 2019.

SILVA, P. G.; GOY, J. L.; ZAZO, C.; BARDAJÍ, T. Fault-generated mountain fronts in southeast Spain: geomorphologic assessment of tectonic and seismic activity. Geomorphology, v. 50, n. 1, p. 203-225, 2003.

SOARES, P. C.; FIORI, A. P. Lógica e sistemática na análise e interpretação de fotografias aéreas em geologia. Notícia Geomorfológica, v. 16, n. 32, p. 71-104, 1976. 
SOUZA, A. S.; FURRIER, M. Técnicas de mapeamento geomorfológico aplicadas em escala de detalhe. Rev. Bras. Geomorf. (Online), v. 20, n. 1, p. 89-103, 2019.

SOUZA, L. S. B.; ROSSETTI, D. F. Caracterização da rede de drenagem na porção leste da ilha do Marajó e implicações tectônicas. Rev. Bras. Geomorf. (Online), v. 12, n. 1, p. 6983, 2011.

STRAHLER, A. N. Quantitative analysis of watershed geomorphology. Eos, Transactions, American Geophysical Union, v. 38, p. 913-20, 1957.

SUGUIO, K. Dicionário de geologia sedimentar e áreas afins. Rio de Janeiro: Bertrand Brasil, 1998.

SUGUIO, K. Geologia do Quaternário e mudanças ambientais. São Paulo: Oficina de Textos, 2010. 